\title{
Anxiety Disorders in Dogs
}

\author{
Miguel Ibáñez Talegón and Bernadette Anzola Delgado \\ Centre of Behavioural Medicine, Animal Production Department, \\ Veterinary Faculty, Universidad Complutense, Madrid \\ Spain
}

\section{Introduction}

Dogs have been one of the closest domesticated animals to men who live with them, and in the majority of cases bond in such a way that they represent another family member, reason why their behaviour affects the common welfare directly. Changes in dogs' behaviour represent a serious problem that threatens not only the physical integrity and general wellbeing of the dog but also that of the people around it. This way, studies focused on resolving animal behaviour problems are indirectly helping in enhancing the family's life quality and even the community's; likewise they reduce the pet's home exclusion risk, since the majority of dog behaviour problems usually lead into the dog's sacrifice or abandonment. All of these situations frequently cause anxiety problems in humans.

Anxiety is a common reason of consulting in Animal Psychiatry. Of all the treated patients in the Service of Clinical Ethology of the Veterinary Faculty of Madrid, an approximate 88\% showed anxiety-related disorders. Studies made by other authors also show numbers similar to ours which leads us to say that the majority of dog behaviour disorders are accompanied by anxiety. This is the reason why they are considered an important problem in the behaviour veterinary medicine.

The majority of behaviour problems related to anxiety or fear that can be found in dogs fit in the normal adaption answers categories, being considered abnormal in the situations that represent a conflict with the animal's environment. It's normal for dogs to respond with fear to some stimuli that are unknown to them and to which they weren't introduced. It's normal to show aggressive behaviour when confronting an individual that is perceived as a threat and from whom there is no escape, and to use aggression more quickly in these situations as a defence mechanism.

\section{Etiology}

The presence of a significant change in the animal's life or those situations capable of producing chronic or post-traumatic stress, result in the alteration of the animal's homeostasis and an adaptation disorder, causes of anxiety disorders (Bousoño et al., 1999; Brousset et al., 2005). There are several factors that predispose towards anxiety, such as genetic factors and experiences during development and learning. The knowledge and study of these elements is essential for the correct diagnosis and application of the ideal therapy. On the other hand, aside from the intrinsic factors, stimuli coming from the 
environment or the lack of said stimuli belong to the realm of the acquired and, are more influential during the early stages of life; likewise, the lack of control and prediction of the environment also act as influential factors. These imbalances are responsible of the apparition of a psychological conflict, which produces anxious responses, which limits the individual to co-exist in equilibrium with its environment, specially resulting into a social malfunction.

\section{Anxiety disorders}

Several definitions for anxiety disorders have been proposed, all of them depending on the different authors' interpretations. In general, it is accepted that the majority of behaviour disorders are related to anxiety. Overall (1997) stipulates a link between stress and the apparition of anxiety. On the other hand, anxiety is the apprehensive anticipation of a stimulus or situation that the animal perceives as unpredictable or dangerous, adopting a preparation and answer behaviour towards the situation or stimulus that might occur (Beata y col., 2006).

Anxiety is pathological when it is continued or grows in an endogenous way without environmental conditions justifying it, becoming uncontrollable by the dog. This type of anxiety present in pathologies such as phobia, separation anxiety and many ways of handling fear, make the dog enter a self-stimulation spiral which enables it to reach a state of tranquillity and homeostasis. This sort of anxiety requires pharmacological treatment; otherwise, it could result into the worsening of the behaviours with which it is associated, and even depression.

The most frequent anxiety-related problems are: separation anxiety, generalized anxiety, aggressiveness, fears, phobias and obsessive-compulsive disorders.

\subsection{Separation anxiety}

Dog's separation anxiety is defined as the behavioural disorder which appears when a dog is left on its own at home or when it is separated from its owners (Sherman and Mills, 2008). It's common in individuals that haven't done a correct detachment, a particular period in their development around the time of puberty where they see that the braking of the affective bond is made by the mother. Signs of separation anxiety in dogs are shown in the situations in which the subject is unable to be with the owner or with the person to whom they are attached (Pageat, 2000).

Separation anxiety may be related to stress signs caused by situations, more frequent in time, such as the dogs being left alone for long time intervals because of the owners' normal habit, or because of restrictions in the social interactions with other dogs, exploratory behaviour and physical exercise (Sherman and Mills, 2008). Likewise, the lack of a physical and social environment for the dog causes a state of boredom and frustration, which can become accumulative and generate separation anxiety.

Symptoms of this disorder frequently appear when the animal perceives that it is about to be left alone, being more obvious when the owner goes out, and becoming more intense between 30 and 60 minutes after leaving. These behaviours were described and numbered by Overall (1997), under which we find excessive vocalization (increase in whining, howling and barking), destructive behaviour (especially directed at objects frequently manipulated by the owners' and that carry their smell), restlessness (manifested as an exacerbated exploratory behaviour), inappropriate defecation and urination, hyper-salivation and escape 
attempts. However, not all dogs that come to the clinic with this disorder show all of these symptoms, it's not only possible to see one, two or all of them at the same time, but also other more uncommon symptoms such as anorexia, vomits and acral dermatitis due to licking. All of these behaviour changes are accompanied by a stress indicative physiological answer. Dogs with separation anxiety are described by their owners as "very clingy", it's common that they follow one or more family members step by step; trying to go with them into all of the house's rooms. This tends to intensify itself near the owner's departure. It is also typical that owners describe their dogs' welcoming as an excessive effusive reaction (Manteca, 2003).

\subsubsection{Etiology}

Normally, 2-3 month old puppies are separated from their mother while still being strongly attached to them, which can cause a tranquilizing effect and a fundamental support for them to develop all of their behaviours. When the separation happens, the pup suffers an illstate which can manifest itself with whining during the night and the lack of appetite, from which the animal develops an adaptive behaviour in search for a balance, establishing a new bond of attachment with one of the owners, this being very positive for the puppy because it allows it to finish its development. Under natural circumstances it is the mother that systematically begins this rupture, which in many occasions doesn't happen in the bond created by the puppy and his owner. The owner continues to respond to the dog's demands, which has already reached puberty, this provokes a hyper-attachment that is nothing but affective dependence, which will be the origin of separation anxiety (Pageat, 2000).

In our clinic we have been able to see that there are situations that frequently result into a separation anxiety disorder, such as those where the dogs, being used to a continuous human company are left alone for the first time as well as the situations during which the dog and owner are constantly together during a long period of time (because of vacation, sick leave or unemployment). Likewise, separation anxiety can arise after the dog has suffered a traumatic event, such as a time period spent in a shelter or dog pound, or after a change in the routine or family structure (child emancipation, modification in the working schedule, moving to a new home, or a new pet or person in the house). Nevertheless, although it is important to take them in consideration when making a diagnosis or when preventing, separation anxiety does not necessarily present itself after one of these situations. Within the possible factors, genetic predisposition has also been mentioned; however it has not been demonstrated.

\subsubsection{Diagnosis}

The clinical record should be done via questionnaire that can provide all the possible information about the dog's daily routine related with food, defecation and urination habits, properties of the physical surrounding, social interaction (with other animals as well as with people from their surroundings), physical exercise and the dog's rest. All of this information is focused on obtaining a better knowledge about the dog-owner relation and to evaluate if the dog has, qualitative and quantitatively speaking, all of its basic needs covered. Questions that might add information about the dog's behaviour prior to the owner's departure should be considered as well as the circumstances under which such anxious behaviours are triggered should be determined precisely. It is also important to know the dog's attitude when the owners return home. Horwtiz (2006) says that the behaviour's time 
sequence is important to establish a diagnosis, there are studies that affirm that the typical separation anxiety behaviour presents itself between 5 and 30 minutes after the dog is on its own at home (Borchelt and Voigh, 1982).

It can be suspected that a dog suffers from separation anxiety when it shows one or more of the following symptoms: destructive behaviour, inappropriate elimination and excessive vocalization (Scopelliti and Bracchi, 2000). Dogs that have separation anxiety with a high level of owner dependence show each of the followings symptoms:

- A tendency to follow the owner through out the whole house seeking to maintain a constant physical contact.

- The increase of physical distance with the owner triggers some anxious conducts in the animal.

- When the owners return home the dog shows excessive enthusiasm.

Scopelliti and Bracchi (2000), indicate that from the category of dogs with separation anxiety, the following dogs can be excluded:

- Dogs younger than 6 months

- Dogs that do not show destructive behaviour or that if they do, they do it in front of the owners.

- Spontaneous episodes.

- Destructive behaviour or aggressiveness-related vocalization

- Inappropriate elimination behaviour (urine) linked with territorial marking in males or with the inappropriate elimination related to physical illnesses.

\subsubsection{Differential diagnosis}

According to the symptoms, the differential diagnosis proposed by Horwitz (2006) for the separation anxiety firstly includes for destructive behaviour cases: destruction as if playing, hyperactivity, lack of physical exercise, storm and noise phobias, territorial behaviour and fear. When there are signs of excessive vocalization, playing, fear or phobia; external stimuli and territorial behaviours should be considered. Inappropriate elimination is a symptom that should discard: fear, improper training, inaccessibility to the place of elimination, physical sicknesses, submission urination, urine marking and cognitive dysfunction. When there are self-traumatizing behaviours, they should be differentiated from acral dermatitis because of licking, obsessive-compulsive disorder, dermatological problems and neuritis.

On the other hand, (Pageat, 2000) indicates that the deprivation syndrome, sociopathies (dominant dogs tend to stop the departure of other members of the group to which they belong), hyper-attachment of the adult syndrome and involution depression should be discarded.

\subsubsection{Treatment}

The efficient treatment of separation anxiety should include teaching the dog how to tolerate the owner's absence and correcting the specific problems of destruction, barking and elimination (Landsberg et al., 1998). It is vital to convince the owner of the need to break the existing hyper-bond and to teach and involve said owner in the fulfilment of the therapy. Treatment must include environmental enrichment to reduce anxiety symptoms and minimize the tension present at home, which will allow the therapy to work. Any possibility that the dog might respond with anxious signs must be eliminated, thus leaving the dog alone must be avoided; in case that it should happen, it should be done in a safe place where 
the dog won't hurt itself or destroy any objects. Activities that boost the dog-owner interaction such as physical exercise and games must be indicated to increase the dog's wellbeing, as well as reinforce with food treats any wished behaviour (Sherman and Mills, 2008).

\subsubsection{Pharmacology}

It is necessary to control anxiety with anxiolytic drugs to encourage the behaviour modification therapy and to achieve short-term improvements that will motivate the owner in completing the treatment (see dosage table and anxiolytics' indications for dogs). Better results have been obtained for the treatment of separation anxiety when combining a behaviour modification program and a pharmacological treatment, rather than just using the behaviour modification program (Landsberg et al., 2008; Simpson et al., 2007). The aim is to reduce anxiety and fear as fast as possible as to establish an appropriate emotional balance in the dog so that it may respond better to the behaviour modification program (Sherman and Mills, 2008). The use of a benzodiazepine for four weeks, combined with fluoxetine (a selective inhibitor of the serotonin reuptake) has show to be efficient in controlling the signs of anxiety (Ibáñez and Anzola, 2010).

\subsubsection{Behaviour modification techniques}

The goals of behaviour modification techniques, desensitization and counterconditioning, that are used in the separation anxiety treatment tend to diminish the anxiety that is associated with the owner's departure, reduce the over-attachment and hyper-link between the owner and the dog and teach the dog how to remain home alone, without anxiety (Horwitz, 2006).

Behaviour modification tries to avoid that the dog feels anxious and that it may remain tranquil while the owners return home. It must comprehend that the owners always return once they have left: for this, the dog must be given the opportunity and all the time that it may require. The anxiety that is produced during this time interferes with the learning and so it is necessary to propose an ansiolytic pharmacological treatment that will favour the establishment of the animal's cognitive abilities. It is very important that during this first period of treatment, the dog should not be left alone at home; the owner will have to provisionally resolve this problem by finding a place other than the home for the dog and offer the necessary means so that it does not miss his company.

Firstly, the owner must have control over his pet. To increase the owner's control over the animal, he will practice basic obedience exercises such as the commands of sit and stay. It is also necessary to practice relaxation techniques through massage routines and conditioning using treats every time the dog controls its anxiety, this way behaviour opposite to anxiety is reinforced. Once this first step is achieved, a technique based on learning by desensitization is begun, to get the animal to accept or tolerate the owner's departure from home. To obtain this, a progressive form of departure is programmed which will allow the animal to predict, through the signals that it receives, the owner's exit. Systematic desensitization is a technique that has been successfully used in humans and pets. There are recent studies (Botler et al., 2001) that claim that systematic desensitization is a key and fundamental element in the treatment of dogs with separation anxiety.

Guideline to follow:

- Begin the normal routine departing activities (get dressed, grab the keys, etc.), make the dog get used to said stimuli. The owner must proceed calmly and ignoring all of the 
dog's responses, sitting in a relaxed way without leaving the house. Once a more relaxed attitude from the dog has been achieved, the owner can move on to the following step.

- Begin as indicated in step one. However, instead of sitting down, the owner should head towards the exit door, open it without leaving, then closing it and sitting down. This must be repeated various times through out the day, until checking that the animal responds with complete tranquillity.

- The following step consists on repeating the previous two, but this time remaining outside for a moment without moving or entering, then sitting calmly on the sofa. Repeat until it is assured that the dog tolerates the situation.

- Next, leave and close the door for a few seconds, then open it, enter the house and sit again on the sofa, trying to accustom the dog in tolerating short term absences, starting with a few seconds. The routine will be repeated and the dog will be given a signal like "later", leaving and coming back in a minute. The return must be made as something normal, ignoring the dog.

Proceed gradually from one step to the other and before taking on the following, repeat until the dog shows no sign of anxiety. All the possible ways of leaving home that last less than 10 minutes must be practiced. Many departures can be made per session if the dog manages to relax enough in between them. Once the dog can accept short-term outings (30 to 60 minutes), it will normally be able to tolerate longer intervals of time, between 3 and 8 hours. However, at the beginning the steps should be taken slowly.

\subsection{Generalized anxiety}

In generalized anxiety the animal shows a constant and crescent reactivity, alertness and exploration, and a great motor activity that interferes with a normal social interaction. When anxiety is constant, it continuously alters the individual's behaviour and it manifests itself as an inhibited stated associated with the production of substitutive activities (Pageat, 2000). When the environment lacks stimuli or they are few, the described signs appear very frequently, without the need of the existence of a triggering stimulus.

\subsubsection{Diagnosis}

Generalized anxiety is shown as a disorder where a constant exhibition and growing hyperreactivity, motor activity, alertness and exploration are shown. Like in other anxiety-related disorders, the main symptoms may vary, frequently being nervousness, trembling, muscular tension and palpitations between others. These signs may present themselves under the complete absence of a triggering stimulus. According to what has been established for diagnostic criteria DSM-IV and CIE-10 for generalized anxiety in humans, it is state that manifests anxiousness in a persistent and infinite way, under no predominant environmental circumstance in particular. Generalized anxiety is not exclusive to human beings, having similar behaviours in other animals such as dogs been seen (Overall, 1997).

As a diagnosis reference we can use the information given by Diez (1991) who grouped generalized anxiety symptoms in four conceptual units, which help understand them better, and can be applied in dog's generalized anxiety in accordance to our criteria, since we can easily observe some of the signs or signals described below:

1. Apprehensive expectation. The patient feels apprehensive, generally preoccupied and ruminative. It anticipates that something bad will happen to him (fainting, lose control 
or dying) or to the people around him (sicknesses, accidents). Inner restlessness appears the feeling of threats, vague fears, insecurity, sensation of being empty, feeling of nothingness and dissolution of the self.

2. Motor tension. It refers to finding the patient trembling, restless, startled, shivering, tense, subject to muscular pain, easily fatigable and incapable of relaxing. Frequent blinking, tense brow and face, unstable pace, hyperactivity, nervousness and restlessness are also detected. The underlying common characteristic is an increased striated muscular tone. Behavioural manifestations can go from extreme excitement to stuporous inhibition, in extreme and infrequent cases.

3. Autonomic hyperactivity. Palpitations, respiratory fatigue, nausea, thamuria, dizziness, sweating, abdominal pains, trembling and cold and wet skin. To this we would have to add mydriasis, vasoconstriction, diarrhea and chest tightness.

4. Alertness and Scrutiny. Anxious expectation can be seen as "sentinel behaviour". The patient is nervous, impatient and irritable. The subject is alert, hyper vigilant, has movement difficulty, insomnia, interrupted sleep and evident fatigue when waking up.

In a dog's case it isn't possible to know if it has any premonitory thoughts, however, an apprehensive attitude is obvious in the majority of the cases that are diagnosed with generalized anxiety and that come to the clinic.

\subsubsection{Treatment}

\subsubsection{Behaviour modification techniques}

Counterconditioning and desensitization techniques are the most used in the treatment of anxious dogs. Through obedience and learning techniques, the dog is taught how to show a new adaptive behaviour in presence of the stimulus that causes the anxiety, and that is completely incompatible to the undesired behaviour. The first thing the dog must learn is to show the substitutive behaviour under situations that do not trigger the anxious response and later respond in the same way under the triggering stimulus' presence. This exercise will be done gradually, allowing the animal to elaborate an adaptive strategy. The stimulus exposure time as well as the presentation degree must grow gradually while the animal gets used to it or becomes impervious to it and said wanted behavior must always be reinforced with a treat (Overall, 1997). A detailed protocol must be designed for each particular case, with all the exercises to be made so that the owner may work in a precise way and that it may be used to analyse the animal's progress in the following weeks.

\subsubsection{Pharmacological treatment}

In these cases pharmacological treatment is necessary since anxiolytic medication facilitates the learning process of behaviour modification techniques in dogs. The treatment with ansiolytics should last between 30 to 60 days, once the animal has acquired a normal behaviour or achieved a great improvement; the dosage will start being gradually reduced during 10 or 14 days, to prevent collateral effects caused by the abrupt interruption of the therapy (Overall, 1997). See table of ansiolytics administration, dosage and indications for dogs.

\subsection{Aggressiveness}

Aggressiveness has been identified as one of the most frequent problems in dogs. A study carried out in Canada concluded that an approximate 15\% of dogs, out of more than 3000, had bitten a family member at some point. In the United States alone approximately 2 
million people are bitten by dogs every year and it is the cause of 10-16 deaths, this makes canine aggression an important problem for public health as well as a public danger (Manteca, 2003). In other countries including Spain there isn't a significant difference with the described data. This is why it is necessary that the owners of aggressive dogs urgently evaluate what degree of danger their dogs represent and that they find professional counselling to correct mentioned above problem (Landsberg, 2003). These statistics could fall short if we considered that aggressiveness in dogs is occasionally a desired behaviour for those owners that have wanted to train them as guard and defence animals. In this sense, Overall (1997) indicates that some animal owners consider their pets heroes, rather than potentially aggressive dogs, when having been aggressively defended by them from attacks or other people's threats in the street or at home.

Pageat (2000) defines aggressiveness as a reactive state characterized by a higher probability of triggering an aggression. The aggressive subject reacts more often than others, producing aggressions. Aggression includes a great variety of behaviours from subtle gestures or corporal postures and facial expressions, to explosive attacks (Landsberg, 2003).

As per Mertens (2006), the dog learns how to be aggressive in order to achieve a goal, this happens when the aggression allows the dog to achieve control of the situation, and the learnt response is even more intense when rewarded either by petting, talking, or through certain gestures and postures from the owner towards the dog. Overall (1997), compares aggression in dogs with diabetes, stating that neither is curable, but controllable thanks to a well established diagnosis and a correctly applied therapy. It has been proven that there is a link between low concentrations of serotonin in the brain and spine and an increase in aggressiveness (Brown et al., 1979).

Pageat (2000) defends that patients with anxiety become irritable and can easily develop aggressiveness. Other authors such as Reisner (2006) also linked anxiety and aggressiveness when explaining that dogs that bite their owners, even inside a social context, their motivation can be based almost entirely on the anxiety that they are suffering. Some types of aggressive behaviours have been reduced in frequency and intensity with the use of psychotropic drugs that increase serotonin levels (Fuller, 1996; Oliver et al., 1995). The American Psychiatric Association doesn't consider aggressiveness in humans a separate diagnostic category; aggression is the main problem in a great variety of psychiatric disorders, which, according to Dodman and Shuster (1998) also apply in veterinary medicine.

\subsubsection{Etiology}

The development of an aggressive behaviour in dogs is a complicated and multifactor process. The expression of the behaviour can be influenced by many factors, such as the perinatal ones that include the extra uterine environment and the interactions with the mother and the siblings. Experiences acquired during the learning and socialization period, as well as other biological factors also influence in aggressiveness (Haug, 2008). On the other hand, a medical problem can increase irritability which could later trigger an aggressiveness disorder or worsen the already existing aggressiveness problem. This is why, it is essential to discard any possible medical cause that might provoke or catalyse aggressive behaviour, such as, amongst others, hepatic problems, intracranial neoplasm, cerebral hypoxia, endocrine disorders, infectious sicknesses (for example, rabies, canine distemper), disorders in the animal's development (hydrocephaly), intoxications (due to metals, 
organophosphates), apoplexy attacks, traumas or other causes that might cause pain, or an increase in the prolactine concentration induced by drugs, or during a false pregnancy (Landsberg, 2003, Mertens, 2006).

The manifestation of an aggressive behaviour may be influenced by the environment, a determined situation or because of certain people's presence. In this sense, we have mentioned that learning is an important factor in the development of an aggressive behaviour. Mertens (2006) explains that basically, the dog learns to be aggressive in order to achieve a goal, following the principal of instrumental conditioning and adds that any daily encounter of the dog with people, dogs or other animals can produce an important impact in the development of unwanted behaviours, including aggressiveness. Many situations that involve the owner may result in aggressiveness related conflicts, such as those that can happen during walks when the dog is tied up or loose or wondering around without supervision. Likewise, barking at the pedestrians through the house's window or during the time the dog spends in the fenced garden. In these cases the owner tends to reinforce the aggressive behaviour with the behaviour he uses in the previously mentioned situations such as touching, petting, pushing or throwing, talking (appeasing or by verbal reprimands) and through gestures and postures that include visual contact, corporal postures and emotional responses.

\subsubsection{Types of aggressiveness in dogs}

\subsubsection{Dominance aggressiveness}

Dominance aggressiveness is one of the most frequent dog aggressions towards people (Manteca, 2003). It is more frequent in males and in those animals that have reached puberty; signs may be seen at age 3 or less (Landsberg, 2003). Depending on the motivation, there can be two types of dominance aggressiveness which can receive two different denominations: competitive dominance aggression and aggression related to social status or the hierarchy in the man-dog relation (Mertens 2006). In the competitive form, the aggression is frequently done in those situations where a resource has enough value as to fight for it. Pageat (2000) considers aggressiveness to be related with social status, or a hierarchic conflict, such as an alteration in the social relationship between man and dog which can present itself in a vague context, which is denominated sociopathy and that affects the social group and not the individual. On the other hand, Overall (1997) indicates that dominance aggressiveness is the expression of a complex multifactor disorder that is influenced by the social context and the animal's anxiety level.

\subsection{Diagnosis}

It is diagnosed through the animal's history or the direct observation of its interaction with its owner, where directed aggression towards the owner can be observed in situations where the highest spot of the hierarchy, assumed by the dog, is threatened. This disorder is made of two very well differentiated elements: aggressive behaviour and dominance exhibition. This is why, the diagnosis isn't only obtained based on aggressions directed towards the family, but also on the dominance indicating corporal attitudes that the dog shows (ears pulled forward, high tail, fixed staring, trying to be physically on top of the family members). It is also possible that the animal demands being petted or that it stops members of the family from accessing certain places of the house (Landsberg, 2003).

Because of its relation with anxiety, the manifestations of dominance aggressiveness are extremely variable, from aggressive behaviour demonstrations which are well defined and 
that are associated to a clear affirmation of control, to very subtle vocal expressions. The difference is how the dog perceives and uses the information obtained from the encounter. The motivation for aggression may vary depending on the context or situation in which the encounter happens, for example a famished dog may attack when it assumes that another individual may stop its access to food, as well as other dogs that react aggressively if a person tries to take away their favourite resting spot; in other cases they compete over toys or for the owner's attention (Overall, 1997). Sociopathies are alterations that appear in the context of an ambiguous relation, which means we won't diagnose this pathology in dogs that completely dominate their owners, but in those animals whose hierarchic situation is vague due to the attribution of prerogatives that are usually associated to the status of being dominant, while the owner takes on a dominant position in hierarchy significant situations. As a consequence signals such as aggressions, hierarchic urination, false pregnancies and destructive behaviour may appear between others (Pageat, 2000). Aggressive behaviour may be directed to one or more members of the household, depending on the relation with the dog, their relative status and their ability to control the dog (Mertens, 2006)

\subsection{Behaviour modification treatment}

Prior to anything else, measures involving the environment must be taken, such as physical barriers to avoid injuring human beings and also other animals, and teaching the dog how to wear a muzzle. Punishment and confrontation must be avoided at all costs. Therapy will begin by ignoring the dog completely during a period of time, afterwards to be ignored systematically, which implies not answering to any request of interaction made by the dog as it would increase its control.

The owner is to begin any sort of interaction, ignoring the dog's initiative to establish any sort of communication. The dog's access to his valued resources is to be controlled, and only if the dog obeys an order, for example "sit", it will be rewarded with the resource. It should also be avoided that the dog repeats aggressive manifestations, detecting all of the situations in which they usually appear. The reinforcement of basic education should be done to acquire a greater control over the dog in all of the situations. It is recommended to practice obedience exercises with the leash and muzzle if needed for ten minutes on a daily basis. As behaviour modification techniques, desensitization and counterconditioning are recommended.

The treatment's protocol is based on reducing the stimulus that induces the aggression to the point where the dog doesn't react. The time exposed to the stimulus is increased as it becomes better tolerated, avoiding at all costs an aggressive response, but if so, the treatment is to be restarted from the beginning (Overall, 1997; Mertens, 2006).

\subsubsection{Intraspecific aggressiveness}

This sort of aggressiveness happens between individuals from the same species. Dogs may be aggressive towards other dogs the same way they are aggressive towards people as we have previously mentioned. There are two different forms, depending to whom the aggression is directed: towards unknown dogs and to the ones with which they live, these are known as "fraternal rivalry" and "sociopathy" (Pageat, 2000). Fights between unknown dogs are more common; however, they're less harmful than those between known dogs and predominantly imply males that do not know each other (Mertens, 2006).

When conflictive situations appear in dogs that live in groups ( 2 or more) the most classic symptomatology is the increase in frequency of the hierarchic aggressive behaviours. This happens because of an alteration in the hierarchic organization, in which the owner's 
presence is a factor that provokes the aggression, since the tendency is to interfere in said situation, which produces a worsening and perpetuation of the conflict, because it stops the conflict from developing naturally until one of the protagonists submits. The information about the stimuli that provoke the fights is fundamental to establish how to act in these situations. This sort of aggression tends to happen in the situations that include competing over valued resources and whose goal is to establish a dominance- subordination relation (Mertens, 2006).

\subsection{Diagnosis}

Dogs that attack unknown dogs may have different motivations. The diagnosis should be accompanied by defining the subjacent factors such as fear, territoriality, competition or a learnt behaviour consequence of a specific training or an unintentional or unnoticed reinforcement. These factors may occur in different combinations and aren't exclusive between themselves. To determine the dog's motivation, everything related to corporal postures, the victim's characteristics, place of fighting, situations that cause the fights and the responses made by the owner in these situations should be observed (Overall, 1997).

Diagnosing aggressiveness between dogs that know each other is more common in same sex dogs and it implies the existence of one of the two following elements: alteration of the behaviour that appears after introducing a new individual to the pack, or alterations that appear after the beginning of the sexual maturity of one of the pack's members. These elements are associated to the impossibility of the animal's ability to carry out the combat until the point of submission of one of the adversaries or the impossibility for the defeated to stay away from the group.

For the diagnosis it is also interesting to observe if there is an increase in the aggression's frequency, urination and hierarchic mounting (Pageat, 2000). Dogs with this type of aggression suffer a high state of anxiety which doesn't allow them to understand their role in the hierarchy (Overall, 1997). The subordinate dog may avoid encounters, give up his place to the other dog and take on submissive postures when the other dog approaches. The highest rank individual tends to respond when the submissive tries to access a resource (Mertens, 2006).

\subsection{Behaviour modification treatment}

Treatment directed towards aggressiveness between strangers consists mainly on behaviour modification therapy. The owner's control over the dog must increase through obedience, doing basic education exercises daily meant to avoid and control aggression towards other dogs. Attacking dogs must be controlled with a muzzle and leash in public places to prevent injuries. Owners should work with their dogs desensitization and counterconditioning techniques to replace the unwanted behaviour with the wanted behaviour such as sitting. As soon as it obeys it must be rewarded with a treat. This exercise should begin at a distance that will allow the dog to stay calm and centre its attention towards its owner; this distance should be reduced as the dog is capable of tolerating the approach without showing any signs of aggressiveness. It is convenient to practice these exercises daily in short 10 to 20 minute sessions, once or twice a day (Overall, 1997; Mertens, 2006).

In the treatment of aggressiveness between known dogs it is fundamental to inform and the counsel the owner in the meaning of the hierarchies and the canine expectations in the group, for the compliance of the proposed rules. Therapy should be systematic and should allow the group to reorganize using its own mechanisms. About the environment: the separation of the dogs by physical barriers is indicated. 
First of all the dogs' hierarchic rank should be established and once it is set which is the highest ranked dog, you should insist on conveniently organizing the space, allowing the submissive dogs to stay away from the high ranked dog's sight. The subordinate dog should be ignored, at least for a time, and receive the owner's attention, but not at the expense of the dominant dog's attention time. The dominant one, will go through the doors first, will eat first, receive exclusive attention from its owner and will have access to its favourite resting spots (Mertens, 2006). Lastly, castration has also been a recommended technique which is relatively successful, but it should be applied over the subordinate and only if its inter-male aggressiveness.

\subsubsection{Territorial aggressiveness}

Territorial aggressiveness tries to stop intrusion in the territory (Pageat, 2000). According to Mertens (2006) territorial aggressiveness is mainly protective and, because of this, can be based on fear. A fear response is triggered by a perceived threat towards a valued resource. The majority of individual approaches towards the territory will pass and disappear; however, the fact that an individual disappears may serve as a powerful reinforcement of the aggression. It presents itself when the aggressive behaviour is directed towards a person or animal that is not considered part of the pack. Aggression may be directed towards people or animals that approach a member of the family or the property perceived by the pet. The term perceived property is used because there is no guarantee that the dog may know the limits of the conventional property (Landsberg, 2003).

\subsection{Diagnosis}

The key aspects of the diagnosis are that this sort of aggressiveness only shows itself towards strangers and only when they enter what the dog considers to be its territories (Manteca, 2003). Signs are the typical aggressive attitudes (upright ears, tail held high with constant wagging, an assertive posture with the weight directed forward, onslaught and biting) and vocalization (growling, barking, etc). This behaviour can be observed in males, as well as females and it generally appears for the first time before the age of 3 (Landsberg, 2003).

\subsection{Behaviour modification treatment}

The territorial aggressiveness behaviour modification treatment should be mainly directed to avoid damages towards people and other animals through physical barriers. It is equally recommended to isolate the dog while there are guests and train him in the use of a muzzle. The reinforcement of obedience through daily basic education exercises is aimed to achieve the owner's control over the dog. The use of desensitization and counterconditioning with the progressive approach of people, under the use of a leash is indicated. Move the exercise towards the entrance, presenting triggering stimuli such as ringing the door bell, letting guests and others in, reinforcing through treats, the wanted behaviours.

\subsubsection{Fear aggressiveness}

Aggressiveness because of fear is one of the ways in which the dog expresses its anxiety towards certain stimuli. An organism that finds itself in a situation from which it is incapable of withdrawing from will respond aggressively. It will attack its adversary without going through the phase of intimidation and without controlling the intensity of the aggression. This aggression tends to be accompanied by neurovegetative manifestations (Pageat, 2000). It is probably the second most frequent form aggression that lacks an organic cause and is directed towards people, after dominance aggressiveness. It happens in the same frequency both in 
males and females. The efficient elimination or withdrawal of the aversive stimulus reinforces this behaviour. Insufficient socialization (lack of contact with people during the sensible period, between 3 and 12 weeks of age) and inconvenient punishment or traumatic experiences are frequent causes of fear aggressiveness (Landsberg, 2003; Manteca, 2003).

\subsection{Diagnosis}

The key element in diagnosing fear aggressiveness is the dog's posture. At first it shows a distinctive defence aggressiveness posture, with its tail tucked between its back legs, lowered crupper, ears directed backwards and, in occasions piloerection. It also tries to not approach the person, avoiding contact and only being aggressive as a last resource. It is important to take in consideration that it isn't always like this, since sometimes it behaves as if it wanted to lunge itself at the person. However, a detailed observation of the animal gives clues that the subjacent motivation is fear, some authors sustain that barking frequently accompanies the signs of this behaviour (Manteca, 2003).

\subsection{Behaviour modification treatment}

The treatment for fear aggressiveness is made of a behaviour modification program that consists of desensitization and counterconditioning. To begin with it is important to consider that dogs should be restrained with leashes and muzzles to avoid damage to humans during their training. Obedience should be reinforced through basic education exercises to obtain the owner's control over the dog. Foresee a whole situations that provoke a fearful response and avoid them. During desensitization and counterconditioning, exposing the animal to stimuli that cause fear should be progressive and controlled, and with the stimulus at a distance.

\subsubsection{Pharmacological treatments for aggressiveness disorders}

Prescribing psychotropic drugs (see anxiolytics table, dosage and indications) may be necessary to allow the dog to learn the necessary techniques to correct each type of problem. Psychotropic drugs tend to place the aggressive dog with high anxiety levels, in a more emotionally equilibrated state. Like selective inhibitors of the serotonin reuptake, tricyclic antidepressants have anxiolytic, anticonvulsants and antiaggresive effects (Crowel-Davis and Murray, 2006).

Anxiolytics may be useful to control aggressiveness in dogs with history of anxious behaviour. To obtain the expected effects at treatment 6 to 8 weeks long may be necessary, while the behaviour modification techniques are applied. In some cases a long term use is necessary, which will vary in accordance to the achieved control over the dog's anxiety. Fluoxetine's effect on reducing dominance aggression has been confirmed after three weeks of administration (Dodman et al., 1996). Equally, in short treatment periods of 10 weeks, it has been confirmed that the use of Psychotropic drugs results in good results in aggressiveness disorders related to dog anxiety, (Ibáñez and Anzola, 2009). This is why the use of Psychotropic drugs is an efficient tool in the therapy of aggressive dogs (see table of anxyolitics, dosage and indications). Psychotropic drugs may have unpredicted effects, including the increase of agitation, which will lead to an increase in the clinical risk (Reisner, 1999), this is why they must be use with precaution.

\subsection{Compulsive disorders}

Dogs suffer from repetitive behaviour disorders which are not well defined. Different authors have used different denominations such as "stereotypes", "obsessive compulsive disorder" or "compulsive disorder". It is a nosological entity linked to anxiety and defined 
by Pageat (2000) as "the presence of obsessions or compulsions serious enough to be responsible of a clear ill-being or a functional handicap".

Compulsive disorders in animals are related to states of anxiety and it is frequent to find these sorts of reactions in dogs that suffer stress. When the stress factor is chronic or unpredictable, the animals tend to show inappropriate or excessive behaviour responses, in order to reduce the level of excitement and consequently the harmful effect of the prolonged physiological response (Dantzer and Mormede, 1985). If the abnormal behaviours are repeated, they can become learn responses when proven efficient in reducing the emotional negative response and the stress associated response. Substitutive behaviours that redirect the energy towards another activity may appear, called displacement activity, which manifests itself in a repetitive and stereotyped way such as licking or "grooming" (Mason, 1991).

Currently there is a dilemma whether dogs really experience the equivalent to human's obsessive compulsive disorder or just a compulsive disorder; in this chapter we use the term obsessive compulsive disorder just like other authors (Beaver, 1999; Overall, 2007; Pageat, 2000) since we consider that animals can have obsessions, although doubtlessly different those of human beings. The obsessive-compulsive disorder is a recognized disorder by animal psychiatry and one of the most disabling (Dell 'Osso et al., 2007). Luescher (1998) calls them compulsive disorders and indicates that they are abnormal behaviours produced in repetitive and invariable ways, and that interfere with normal behaviour. Compulsion is defined as a repetitive and intentional behaviour manifested in a stereotyped way and that presents itself as the response to an obsession; compulsive behaviour is not pleasant, it is executed with the aim to reduce the state of anxiety (Hollander, 1993).

According to Diagnosis and Mental Disorders Statistics guide (DSM-IV) for humans, the obsessive compulsive disorder (OCD) is defined as the presence of obsessions and recurrent compulsions that cause a strong stress or functional alterations (Jang et al., 2010) and which are included in the group of anxiety disorders by the American Psychiatric Association (2002). The behavior syndrome in animals might not be wholly analogous to obsessivecompulsive disorder in humans, although they might share a similar pathophysiology.

\subsubsection{Diagnosis}

An OCD diagnosis requires that the symptoms provoke a notorious ill-being, with a time determined duration and that it significantly interferes in the animal's normal functioning (Eissen et al., 2009). The course of this disorder is chronic and increases and diminishes in severity, frequently as a reaction to stress. Normally, in humans other psychiatric disorders coexist such as mood disorders, anxiety and psychotic disorders (Dell'Osso et al., 2007). We have been able to observe that in dogs there also exists a relation with mood and anxiety. The proportion in the animal population is high due to genetic causes, mainly because of the procedures of genetic selection, which include inbreeding as a common practice (Robins et al., 1984).

In animals, obsessive-compulsive disorders have been divided in three categories: conflict behaviors, emptiness and stereotypes. Conflict behaviors have been associated to restriction and impoverishment conditions, for example cannibalism, urine suction and tics (Wiepkema, 1980). Empty behaviors or empty activities are unconscious actions practiced in the absence of the stimulus under which they would be expressed and that do not pursue any purpose; in dogs empty behaviors such as licking, self-mutilation and masturbation are typical (Landsberg et al., 2003). The diagnostic signals of stereotyped behaviors in dog may vary a lot, and some may be more frequent than others, such as licking the nose and lips, 
shaking the head, yawning, circling, pacing, tail-chasing, self-mutilation, snapping at the air, excessive grooming, and rhythmic barking (Landsberg et al., 2003; Pageat, 2000).

Stereotypes may have their origin in an organic disorder, thus a neurological exam and a blood analysis are necessary; and in some determined cases a complete dermatological protocol may also be useful. If the problem began when an important change in the environment took place or it appears under determined circumstances, it is probably a stereotype with no organic cause.

\subsubsection{Treatment}

Like in the majority of behaviour disorder cases, the treatment requires the intervention over the animal's environment, the behaviour modification and the administration of psychotropic drugs. For these disorders treatments combining the use of psychotropic drugs and behaviour modification techniques have been effective, especially habituation and counterconditioning (Overall, 1997). The treatment mandatorily associates chemotherapy and a behaviour therapy (Pageat, 2000).

The reduction of anxiety, or the discovery of methods used to reduce the source of excitement and conflict are the first aspects of the treatment to be investigated in compulsive behaviours. Another important aspect to value in the treatment is the incompatibility in the dog-owner relationship, which may cause problems and in a very special way when it involves an incoherent education. Stereotypes have a reserved forecast and the recommended treatment isn't always successful.

\subsubsection{Intervening in the environment}

The environment in which the animal lives must be studied to make sure that the dog has the resources that will offer enough stimulation. Time used for playtime, exercise and attention as well as how they are administered should be analyzed. It is very important to identify and eliminate, if possible, the environmental factors responsible of the compulsive behaviour.

It has been proven that environmental enrichment systems are very efficient, mainly those related to food and social aspects through games with toys or other living beings, if the environment is very poor in stimuli. It is the case of those animals that are locked up for long periods of time on their own in places of small dimensions or with very few occasions of social interaction. In many cases, triggering game sequences where contact with the owner is encouraged resulting in good results which is why it is recommended to practice sports activities where the activity is shared and a correct communication is established between the dog and owner such as that which is done during the practice of "agility". In other occasions, the best treatment is to take the animal to live in a different environment.

\subsubsection{Behaviour modification techniques}

An obedience training program that completes the possible found deficits should be started (Landsberg, 2003). If anamnesis indicated a fear problem or it is associated to an anxiety separation problem, the treatment must include a protocol such as those suggested in each of the cases previously described.

\subsubsection{Pharmacological treatment}

The serotonin reuptake inhibitors (ISRS) and the cognitive-behavioural therapy represent the first line of treatment for OCDs and related disorders (Dell 'Osso et al., 2007). It has been found that clomipramine is effective and well tolerated in the therapy of obsessive compulsive disorders (Seksel and Lindeman, 2001), likewise fluoxetine has resulted efficient as a 
complementary tool in the therapy of this disorder (Ibañez and Anzola, 2009). The drugs that result to be the most useful are clomipramine, fluoxetine and selegiline (Manteca, 2003). It is important to take in account that none of them reduce or eliminate stereotypes in all of the treated cases, which is why sometimes it is necessary to try various treatments before obtaining a satisfactory result. See table of anxyolitics, dosage and indications for dogs.

\section{General therapeutic management of anxiety in dogs}

As we have described in the most important anxiety related disorders, the therapeutic management is the implementation of a battery of combined therapies to reduce the state of anxiety, which will depend on the degree of intensity and if there is an involvement brain neurochemistry. The best tools to correct or minimize behaviour disorders consequence of anxiety are behaviour modification techniques and the use of psychotropic drugs. Therapy must begin with a relaxation protocol which predisposes the animal to a better acceptance of the upcoming treatment. Afterwards, psychopharmacology is used and finally behaviour modification techniques such as habituation, desensitization and counterconditioning.

\subsection{Relaxation}

The first step is to establish a model of tranquil and relaxed responses from the dog when the provocative stimulus isn't present. It is very important that owners recognize their pet's tranquil responses and that they reward them accordingly. It is advisable to include within therapy at least two daily sessions of relaxing massages which must be set in a tranquil place, without any noise and if possible with relaxing background music. It is convenient to do these sessions during 10-20 minutes until making the animal reach a relaxed state in which it almost falls asleep. During the sessions the animal should remain seated or lying down and be rewarded for its tranquil and relaxed attitude. The owner may gradually add some distractions during these exercises, such as clapping or moving a few steps away from the dog and then returning to the initial position (Neilson, 2006).

\subsection{Pharmacological treatment}

Alterations in dog's behaviour are problems that majorly correspond to neurochemical imbalances triggered by high levels of anxiety. It is more and more frequent in veterinary medicine that owners are interested in finding help for their animals which have anxiety related disorders. Psychotropic drugs are used to compensate the imbalance in the chemical substances of the central nervous system. Since long ago, anxiolytic drugs have been used in humans and animals.

In general, psychotropic drugs result in modifying the animal's response capacity to successfully confront external stimuli, helping its homeostasis to improve, which will reduce the levels of anxiety. Anxiety blocks the learning mechanisms, incapacitating the animal to respond efficiently and making it even more susceptible to anxiety, generating a vicious circle. Some behaviour disorders may ne reduced both in frequency as well as severity with the use of psychotropic drugs which produce modifications in the neurotransmitters (Mills and Simpson, 2006).

Tricyclic antidepressants, benzodiazepines and other drugs with anxyolitic properties induce a control over many dog's anxiety (King et al., 2000). Serotonin reuptake selective inhibitors (ISRS) are classified as antidepressants and their use in veterinary is due to its anxyolitic effects. Fluoxetine is the most used in pets to treat behaviour problems and its most frequent use includes the treatment of anxiety (Crowell-David and Murray, 2006). 
Benzodiazepines are part of the most used pharmacological group in the treatment of anxiety nowadays. They are synthetic compounds that strengthen GABA's effects (Cuenca and Álamo, 2005). They are also an alternative to supplement the fluoxetine's effect in the treatment of anxiety (Ibáñez and Anzola, 2009).

\subsection{Behaviour modification techniques}

The main behaviour modification techniques used in veterinary are habituation, systematic desensitization and counterconditioning. Habituation and counterconditioning are use to increase the threshold in which the animal responds to a specific stimulus or situation. This procedure requires the identification and ranking of the aversive stimuli, the animal relaxation training, the identification of the animals responses at an acceptable level, the presentation of the stimuli that trigger the problem, by order of range, and the reinforcement of learning (Mills, 2006).

Counterconditioning leads to the extinction or the control of the unwanted behaviour; this is achieved by teaching the dog another behaviour, in this case wanted, which interferes competitively with the execution of the unwanted behaviour. Once the dog learns how to do the competitive behaviour which is incompatible with the unwanted behaviour, a desensitization technique can be started (Overall, 1997).

\section{Clinical trials}

In the Animal Behaviour Clinic of the Veterinary Faculty, of the Complutense University of Madrid, we have carried out a series of several clinical trials studying a therapeutic efficacy of different drugs in anxiety states in dogs. Psychotropic drugs i.e. antidepressants and anxiolytic and behaviour modification techniques have been used. The efficacy of the used methods in the different dosage regimes has been studied. All anxiety disorders in dogs have been grouped into two general categories in accordance with clinical casuistic: the disorders with and without anxiety and aggressive behaviour.

We have experienced several benzodiazepine drugs together with the fixed therapy. In addition, fluoxetine and a common behaviour modification technique has been also used. The main published results concerned the use of diazepam, while the data on the clorazepate and alprazolam administration have not been published yet. There exists possibility in efficacy discrepancies and adverse events between different benzodiazepines. The possible differences in treatment efficacy in relation to gender and age of the studied animals' also exist.

In the first study 40 dogs from different breeds, age and gender with anxiety disorders were included (Journal of Veterinary Behaviour, 2009, 4, 223-229). Fluoxetine, diazepam and behaviour modification as therapy methods have been used. The dogs were grouped into two diagnostic categories, according to presence or absence of anxiety and aggressive behaviour. The dogs were also classified in 4 other groups: castrated, whole, young and adult. Diazepam was used orally at a dosage of $0.3 \mathrm{mg} / \mathrm{kg}$ once a day for 4 weeks; fluoxetine was given orally and daily at a dosage of $1 \mathrm{mg} / \mathrm{kg}$ during 10 weeks. Likewise, a behavior therapy was started from the first day of the treatment.

Obtained results have shown a great improvement or elimination of the clinical signs in $38 \%$ of the dogs, a minimal or moderate improvement in $31 \%$, while $24 \%$ of the dogs didn't achieve any improvement. There was no evidence of difference in the treatment efficacy between the anxious and aggressive groups; castrated and whole; and young and adult. In addition, a positive correlation between the owner's compliance with the therapy and an improvement results was revealed. 


\begin{tabular}{|l|l|l|}
\hline Drug & Dosage (PO) & Indications \\
\hline Amitriptyline & $1,0-6,0 \mathrm{mg} / \mathrm{kg} \mathrm{q12h}$ & $\begin{array}{l}\text { Compulsive disorders, aggressiveness and } \\
\text { separation anxiety }\end{array}$ \\
\hline Alprazolam & $0,02-0,1 \mathrm{mg} / \mathrm{kg} \mathrm{q} 4 \mathrm{~h}-12 \mathrm{~h}$ & $\begin{array}{l}\text { Generalized anxiety, fears and phobia, } \\
\text { aggressiveness and separation anxiety }\end{array}$ \\
\hline Acepromazine & $0,5-2.0 \mathrm{mg} / \mathrm{kg} \mathrm{q} 8 \mathrm{~h}-12 \mathrm{~h}$ & Noise phobias \\
\hline Buspirone & $0,5-2.0 \mathrm{mg} / \mathrm{kg} \mathrm{q} 8-12 \mathrm{~h}$ & Fears, separation anxiety \\
\hline Clomipramine & $1,0-3,0 \mathrm{mg} / \mathrm{kg} \mathrm{q} 24 \mathrm{~h}$ & $\begin{array}{l}\text { Generalized anxiety, fears and phobias, } \\
\text { separation anxiety, compulsive disorders and } \\
\text { aggressiveness }\end{array}$ \\
\hline Clonazepam & $0.1-0.5 \mathrm{mg} / \mathrm{kg} \mathrm{q} 8 \mathrm{~h}-12 \mathrm{~h}$ & Aggressiveness, Generalized anxiety \\
\hline Chlordiazepóxide & $0.2-1.0 \mathrm{mg} / \mathrm{kg} \mathrm{q12h}$ & Generalized anxiety \\
\hline Diazepam & $0,5-2,0 \mathrm{mg} / \mathrm{kg} \mathrm{q4h}$ & $\begin{array}{l}\text { Generalized anxiety, fears and phobias, } \\
\text { aggressiveness, capricious alimentary } \\
\text { behaviour and separation anxiety }\end{array}$ \\
\hline Clorazepate & $0,5-2,0 \mathrm{mg} / \mathrm{kg} \mathrm{q4h}$ & Generalised anxiety and separation anxiety \\
\hline Doxepin & $3.0-5.0 \mathrm{mg} / \mathrm{kg} \mathrm{q} 8 \mathrm{~h}-12 \mathrm{~h}$ & Compulsive disorders, fears and phobias \\
\hline Fluoxetine & $1.0-2.0 \mathrm{mg} / \mathrm{kg} \mathrm{q} 24 \mathrm{~h}$ & Separation anxiety \\
\hline Haloperidol & $0,05-2.0 \mathrm{mg} / \mathrm{kg} \mathrm{q12h}$ & Compulsive disorders and aggressiveness \\
\hline Imipramine & $0,5-2,0 \mathrm{mg} / \mathrm{kg} \mathrm{q8h}$ & $\begin{array}{l}\text { Urination because of submission and } \\
\text { excitement }\end{array}$ \\
\hline Lorazepam & $0.02-0.5 \mathrm{mg} / \mathrm{kg} \mathrm{q8h-24h}$ & Generalized anxiety \\
\hline Oxazepam & $0.2-1.0 \mathrm{mg} / \mathrm{kg} \mathrm{q6h-24h}$ & Generalized anxiety, anorexia \\
\hline Paroxetine & $0,5-2.0 \mathrm{mg} / \mathrm{kg} \mathrm{q24h}$ & Generalized anxiety \\
\hline Selegiline & $0,5-1,0 \mathrm{mg} / \mathrm{kg} \mathrm{q24h}$ & $\begin{array}{l}\text { Aggressiveness, cognitive dysfunction and } \\
\text { compulsive disorders }\end{array}$ \\
\hline Thioridazine & $1.0-3.0 \mathrm{mg} / \mathrm{kg} \mathrm{q12h-24h}$ & $\begin{array}{l}\text { Generalized anxiety, aggressiveness, } \\
\text { compulsive disorders, fears and phobias }\end{array}$ \\
\hline
\end{tabular}

Charney et al., 2006; Crowell-Davis \& Murray, 2006; Landsberg et al., 2003; Mills \& Simpsom, 2006; Overall (1997); and Simpson et al., 2007.

Table 1. Main drugs, dosage and indications for dogs.

\section{References}

American Psychiatric Association. (2002). Trastornos de ansiedad. In: DSM-IV-TRR Diagnostic criteria. Ed. Masson, S.A. ISBN 0-89042-026-2, Barcelona, p. 211

Beata, C., Horwitz, D., Bowen, J., Fatjó, J. \& Palestrini, C. (2006). Como detectar y tratar la ansiedad en el gato. Focus Royal Canin. Edición especial. Francia

Beaver, B. (1999). Canine Behavior: A Guide for Veterinarians. W.B. Saunders Company. Philadelphia

Borchelt, P. \& Voigh, V. (1982). Diagnosis and treatment of separation related behavior problems in dogs. In: Veterinary Clinics of North America. Small Animal Practice. 12 (4). p. 625-635

Bousoño García, M., Sáiz, PA., González, MP. \& Bobes, J. (1999). Protocolo diagnóstico de los estados de ansiedad. Medicine. 7(106): p. 4969-4971

Brousset, DM., Galindo, F., Valdéz, R., Romano, M. \& Schuneman, A. (2005). Cortisol en orina, saliva y heces: Evaluación no invasiva en mamíferos silvestres. Veterinaria México. 36, p. 325-337 
Brown, GL., Frederick, K., Goodwinb, FK., Ballengerc, JC., Goyerd, PF. \& Majore, LF. (1979). Aggression in humans correlates with cerebrospinal fluid amine metabolites. Psych Res.; 1, 131-139

Botler, R., Sargisson R., Douglas, E. (2011). The efficacy of systematic desensitization for treating the separation-related problem behaviour of domestic dogs. J. Appl. Anim. Behav. Sci. 129, 136-145

Casey, R. (2006). Miedo y estrés. In: Manual de comportamiento en pequeños animales. Horwitz, D., Mills, D., Heath, S (Eds.). 231-242, ISBN 84-87736-61-0, España

Charney, DS., Mihic, SJ. \& Harris RA. (2006). Hipnóticos y sedantes. In: Brunton LL, Lazo JS,Parker KL. Goodman \& Gilman. Las bases farmacológicas de la terapéutica. $11^{\text {a }}$ ed. McGraw-Hill Interamericana. México DF

Crowell-Davis, Sh. \& Murray T. (2006). Veterinary Psicopharmacology. Blackwell Publishing Ltd., ISBN 978-84-200-1098-4, Oxford, p 51

Cuenca E. \& Álamo C. (2005). Glosario básico de neuropsicofarmacología. $1^{\mathrm{a} e d}$. Universidad de Alcalá. España.

Dell'Osso, B., Altamura, AC., Allen, A., Marazziti D. \& Hollander E. (2006). Epidemiologic and clinical updates on impulse-control disorders: a critical review. Eur. Arch. Psychiatry Clin. Neurosci. Sep 7

Dantzer, R. \& Mormede, P. (1985) Stress in domestic Animals: A Psychoneuroendocrine Approach. In Animal Stress. Moberg, GP. Ed. American Physiological Society. ISBN 0-683-06101-1. Baltimore., Maryland USA

Dodman, N. \& Shuster, L. (1998). Psycopharmacology in animal behavior disorders. Blackwell Science, ISBN 0-63204358-X, Malden, MA

Dodman, N., Donnelly, R., Shuster, L., Mertens, P., Rand, W. \& Miczek, K. (1996). Use de fluoxetine to treat dominance aggression in dogs. JAVMA, 209, 1585-1587

Eisen, JL., Yip, A., Mancebo, M., Pinto, A. \& Rasmussen, S. (2009). Phenomenology of Obsessive-Compulsive Disorder. In: Stein DJ, Hollander E, Barbara Olasov Rothbaum eds. Textbook of Anxiety Disorders. American Psychiatric Publishing, Inc ISBN 978-1-58562-254-2 Arlington

Fuller, R.W. (1996) . The influence of fluoxetine on aggressive behavior. Neuropsychopharmacology. 14, 77-81

Haug, L. (2008). Canine Aggression Toward Unfamiliar People and Dogs.. In: Landsberg, G. \& Horwitz., D. Veterinary Clinics of North America. Small Animal Practice. Practical Applications and New Perspectives in Veterinary Behaviour. Elsevier Saunders. 38. (5), 1023-1041

Hollander, E. (1993). Obsessive-Compulsive-Related Disorders. Hollander E (ed). Washington, DC: American Psychiatric Press. ISBN 0-88048-402-0 Washington, DC, pp. 1-16

Horwtiz, D. (2006). Problemas de separación en perros. In: Horwitz, D., Mills, D., Heath, S (Eds.). Manual de Comportamiento en pequeños animales.. 247-261, ISBN 84-87736-61-0, España

Ibáñez, M. \& Anzola, B. (2009). Use of fluoxetine, diazepam, and behavior modification as therapy for treatment of anxiety-related disorders in dogs. J. Vet. Behav. Clin. Appl. Res. 4, 223-229

Landsberg, G., Hunthausen, W. \& Ackerman, L. (2003). Handbook of Behavior Problems of the Dog and Cat, 2nd ed. Elsevier Saunders. ISBN 84-200-0848-6, Philadelphia

Landsberg, G., Melese, P., Sherman, B., Neilson, J., Zimmerman, A. \& Clarke, T. (2008). Effectiveness of fluoxetine chewable tables in the treatment of canine separation anxiety. J. Vet. Behav. Clin. Appl. Res. 3, 12-19 
Luescher, UA. (1998). Pharmacologic Treatment of Compulsive Disorder. In: Dodman, N.H., Shuster, L. (Eds). Psycopharmacology of Animal Behavior Disorders. Blackwell Science, ISBN 0-63204358-X, Malden, MA

Manteca, J. Ansiedad por separación del perro y diagnósticos diferenciales. (2003). In: Manteca, J. Etología clínica veterinaria del perro y del gato. Ed. Multimédica. ISBN 84932811-0-7, Barcelona

Mason, G.J. (1991). Stereotypies: a critical review. Anim. Behav. 41, pp. 1015-1037

Mertens, PA. (2003). Agresividad Canina. In: Horwitz, D., Mills, D., Heath, S (Eds.). Manual de Comportamiento en pequeños animales. España

Mills D.S. (2006). Ténicas de aprendizaje, entrenamiento y modificación de la conducta. En: Horwitz, D., Mills, D., Heath, S (Eds.). Manual de Comportamiento en pequeños animales. España.. P. 59-76

Mills, D. \& Simpsom, B. (2006). Agentes psicotrópicos. In: Horwitz, D., Mills, D., Heath, S (Eds.). Manual de comportamiento en pequeños animales. España

Neilson, J. (2006). Miedo a lugares o cosas. In: Horwitz, D., Mills, D., Heath, S. (Eds.). Manual de Comportamiento en pequeños animales. ISBN 84-87736-61-0, España

Oliver, B., Mos, J., VanOorsschotr, R. \& Hen, R. (1995). Serotonin receptors and animal models of aggressive behavior. Pharmacopsychiatry. 28 (Suppl.2), 80-90

Overall, KL. (1997). Clinical behavioral medicine for small animals. Mosby-Year Book Inc., ISBN 0-8016-6820-4, St Louis

Overall, KL., Dunham, A. \& Frank, D. (2001). Frequency of non-specific clinical signs in dogs with separation anxiety, thunderstorm phobia, and noise phobia, alone or in combination. J. Am. Vet. Med. Assoc. 219, 467-473

Pageat, P. (2000). Patología del Comportamiento del Perro. Pulso Ediciones S.A. ISBN 84-8667154-X, España

Reisner, I., (1999). Agresión canina. Neurobiología, comportamiento y tratamiento. In: Veterinary International. Vol 11. 1, 16-25

Reisner, I. (2006). Visión General de la Agresión. In: Horwitz, D., Mills, D. \& Heath, S. (Eds), Manual de Comportamiento en Pequeños Animales. Ediciones S, ISBN 84-87736-61-0, España

Scopelliti, A. \& Bracchi, PG. (2000). Anxiety caused by separation in dogs. Symptoms, differential diagnosis and treatment. Annali della Facoltà di Medicina Veterinaria, Università di Parma. Vol. 20 pp. 255-270

Seksel, K., Lidenman, MJ. (2001). Use of clomipramine in treatment of obsessive-compulsive disorders, separation anxiety and noise phobia in dogs: a preliminary, clinical study. Aust. Vet. J. Vol. 79, 252-256

Robins, LN., Helzer, JE. \& Weissman, MM. (1984). Lifetime prevalence of specific psychiatric disorders in three sites. Arch Gen Psychiatry. 41: 949-958

Sherman, B. \& Mills, D. (2008). Canine Anxieties and Phobias: An Update on Separation Anxiety and Noise Aversions. In: Landberg, G. \& Horwitz, D. Practical Applications and New Perspectives in Veterinary Behavior. Veterinary Clinics of North America. Small Animal Practice. Elsevier Saunders. Philadelphia. Vol. 38. Number 5, 1081-1106

Simpson, BS., Landsberg, GM., Reisner, IR., Ciribassi, JJ., Horwitz, D., Houpt, KA., Kroll, TL., Luescher A., Moffat KS., Douglass, G., Robertson-Plouch, C., Veehouizen, M.F., Zimmerman, A. \& Clark, TP. (2007). Effects of Reconcile (fluoxetine) chewable tablets plus behaviour management for canine separation anxiety. Vet. Ther. 8, 18-31

Wiepkema, PR, Koohas JM \& Oliver-Aardema R. (1980). Adaptative aspects of neuronal elements in agonistic behavior. ProgBrain Res. 53: 369-384. In: Overall, KL. 1997. Clinical behavioral medicine for small animals. Mosby-Year Book Inc., ISBN 0-8016-6820-4, St Louis 


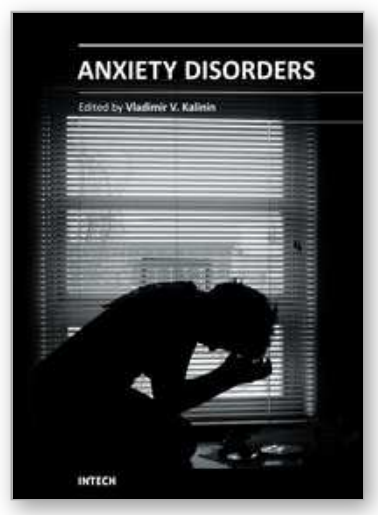

\author{
Anxiety Disorders \\ Edited by Prof. Vladimir Kalinin
}

ISBN 978-953-307-592-1

Hard cover, 324 pages

Publisher InTech

Published online 01, August, 2011

Published in print edition August, 2011

During the last 2-3 decades drastic research progress in anxiety issues has been achieved. It concerns mostly the study of different subtypes of anxiety and their treatment. Nevertheless, the data on anxiety pathogenesis is less elaborated, although here a multidimensional approach exists. It includes neurochemistry, pathophysiology, endocrinology and psychopharmacology. Again, we are able to recognize the multifarious sense of anxiety, and the present collective monograph composed of 16 separate chapters depicting the different aspects of anxiety. Moreover, a great part of book includes chapters on neurochemistry, physiology and pharmacology of anxiety. The novel data on psychopathology and clinical signs of anxiety and its relationship with other psychopathological phenomena is also presented. The current monograph may represent an interest and be of practical use not only for clinicians but for a broad range of specialists, including biochemists, physiologists, pharmacologists and specialists in veterinary.

\title{
How to reference
}

In order to correctly reference this scholarly work, feel free to copy and paste the following:

Miguel Ibáñez Talegón and Bernadette Anzola Delgado (2011). Anxiety Disorders in Dogs, Anxiety Disorders, Prof. Vladimir Kalinin (Ed.), ISBN: 978-953-307-592-1, InTech, Available from:

http://www.intechopen.com/books/anxiety-disorders/anxiety-disorders-in-dogs1

\section{INTECH}

open science | open minds

\author{
InTech Europe \\ University Campus STeP Ri \\ Slavka Krautzeka 83/A \\ 51000 Rijeka, Croatia \\ Phone: +385 (51) 770447 \\ Fax: +385 (51) 686166 \\ www.intechopen.com
}

\author{
InTech China \\ Unit 405, Office Block, Hotel Equatorial Shanghai \\ No.65, Yan An Road (West), Shanghai, 200040, China \\ 中国上海市延安西路65号上海国际贵都大饭店办公楼 405 单元 \\ Phone: +86-21-62489820 \\ Fax: +86-21-62489821
}


(C) 2011 The Author(s). Licensee IntechOpen. This chapter is distributed under the terms of the Creative Commons Attribution-NonCommercialShareAlike-3.0 License, which permits use, distribution and reproduction for non-commercial purposes, provided the original is properly cited and derivative works building on this content are distributed under the same license. 